\section{DUBAI HEALTH PROFESSIONALS PROMOTE HEALTHY SMILES}

Expat dental hygienist and BDJ Team panel member Rachael
England (pictured, second from right) reports from Dubai

$\mathrm{D}$

ubai Health Authority (DHA) has collaborated with Philips and Dentist Direct Dubai to support the launch of the 'Dubai Smiles Healthy' programme at schools in celebration of World Oral Health Day, which takes place annually on 20 March. As part of the programme, DHA and Dentist Direct Dubai are visiting schools to carry out dental checks on students. The head nurse in each school will be trained to spot children with dental problems and teachers will be trained to supervise tooth brushing in class.

Dr Hamda Al Mesmar, Director of the Dental Department at the DHA, said: 'We are pleased to be partnering with Philips and Dentist Direct, to drive awareness on the importance of good oral hygiene, as by 2021, we want to improve and change the overall oral health levels amongst students in Dubai. This new initiative is an excellent way of reaching the students in a way that can influence them from an early age. Oral hygiene is an important issue on our agenda, and through this programme, we will ensure that we reach as many students and parents as we can to drive awareness and behaviour change.

Rachael England, Dental Hygienist at Dentist Direct, said: 'We are delighted to support the Dubai Health Authority. Improving the oral health of children is crucial. We want to encourage young people to adopt good brushing habits and reinforce

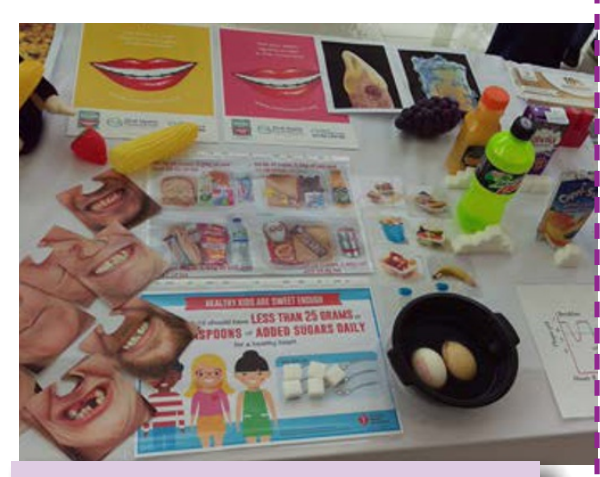

'WE WANT TO

ENCOURAGE YOUNG

PEOPLE TO ADOPT GOOD

BRUSHING HABITS

the message that it is important for both a healthy mouth and body. We want people to make smart decisions about their oral health and help them recognise that they need to give their oral hygiene routine more attention and go for regular check-ups, to achieve better overall health'

In the United Arab Emirates (UAE) 90\% of children suffer from caries. Oral disease is the most common disease in the UAE, followed by obesity, diabetes, cardiovascular disease, cancer and mental illness.



\section{BSDHT}

'First Smiles'

initiative

\section{retarns}

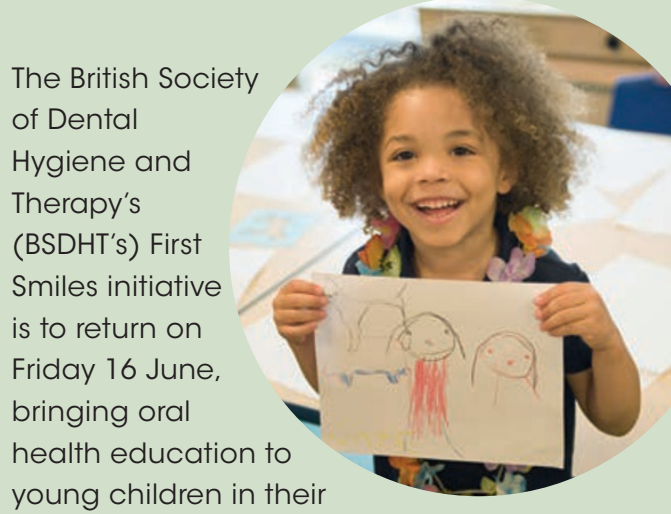

own classrooms.

First Smiles will encourage BSDHT members to enter schools and nurseries across the UK to deliver fun and accessible lessons to children on the importance of good oral health, teaching youngsters the necessary habits needed to maintain a healthy smile for life.

President of the BSDHT, Helen Minnery, said: 'Over the last two years, First Smiles has encouraged our wonderful members from all across the country to reach out to local schools and volunteer their services, and the services of their practice, by visiting local school children to teach them about the importance of good oral health.

'Whether it's their first tooth or their first visit to the dentist, a child's early experiences of oral health can impact on the rest of their lives. That's why it's so important to teach them about their mouths and introduce them to good habits as soon as possible.

'This year we are aiming for our programme to be bigger and better than before; to achieve this we need your help to ensure important oral health messages reach many more children.'

The BSDHT aims to mobilise its members to use their unique skills and knowledge to make a difference to children's oral health. The initiative is open only to dental hygienists, dental therapists and students who are BSDHT members.

BSDHT members who wish to take part and make a difference can find out more about First Smiles at www.bsdht. org.uk/FirstSmiles. 